\title{
Lung-Thorax Compliance in the Artificially Ventilated Premature Rabbit Neonate in Relation to Variations in Inspiration:Expiration Ratio
}

\author{
BURKHARD LACHMANN, GERTIE GROSSMANN, JOACHIM FREYSE, BENGT ROBERTSON ${ }^{(38)}$ \\ Department of Pediatrics, St. Göran's Children's Hospital, Stockholm, Sweden, [G. G.]; Department of Pediatric \\ Pathology, Karolinska Institutet, Stockholm, Sweden [B. R.]; and Department of Pathophysiology, Research Institute \\ for Lung Diseases, Berlin-Buch, German Democratic Republic [B. L., J. F.]
}

\begin{abstract}
Summary
Surfactant-deficient premature newborn rabbits obtained by hysterotomy on day 27 of gestation were tracheostomized at birth, kept in a multichambered pressure-constant body plethysmograph, and subjected to intermittent positive pressure ventilation using a standardized insufflation pressure $\left(30 \mathrm{~cm} \mathrm{H}_{2} \mathrm{O}\right)$. A sequence of various frequencies $(20,40$, and $60 / \mathrm{min})$ and inspiration:expiration (I:E) ratios (1:4, 1:2, 1:1, 2:1, and 4:1) were applied, and the effect of these various respirator settings on tidal volume $\left(V_{T}\right)$ and flow was evaluated by means of a Fleisch tube connected to the body plethysmograph. Irrespective of respirator frequency, increasing I: $E$ ratio from the basic setting of 1:1 resulted in increased $V_{T}$; decreasing I: $E$ ratio had the opposite effect. There was a nearly linear relation between variations in $\mathrm{I}: \mathrm{E}$ ratio and $\mathrm{V}_{\mathrm{T}}$, but the slope of the regression line was steeper at frequencies 40 and $60 / \mathrm{min}$ than at $20 / \mathrm{min}$. At a frequency of $20 / \mathrm{min}$, values $(\bar{X} \pm$ S.D. ) for lung-thorax compliance at I:E ratios of $1: 4$ and $4: 1$ were $0.50 \pm$ 0.26 and $0.99 \pm 0.42 \mathrm{ml} / \mathrm{cm} \mathrm{H}_{2} \mathrm{O} \cdot \mathrm{kg}$, respectively. Corresponding figures for frequency of $60 / \mathrm{min}$ were $0.21 \pm 0.10$ and $0.73 \pm 0.36$ $\mathrm{ml} / \mathrm{cm} \mathrm{H}_{2} \mathrm{O} \cdot \mathrm{kg}$. At the two higher frequencies and low I:E ratios $(\leq 1: 1)$, the duration of the inspiration phase was not sufficient to provide the maximal degree of lung expansion attainable with this insufflation pressure under static conditions. At frequency of 60 / min and I:E ratio of 4:1, the expiration was short enough to prevent zero flow before onset of inspiration.
\end{abstract}

\section{Speculation}

The wet lungs of premature neonates with surfactant deficiency are not ventilated effectively with a conventional inspiration:expiration ratio of $1: 1$, or less. However, by increasing inspiration: expiration ratio to as much as $4: 1$, the viscosity of the fluid in the airways can be overcome, and the lungs can then be ventilated with a lower insufflation pressure. This alternative setting of the respirator should reduce the risk of long-term complications, such as bronchopulmonary dysplasia, in surfactant-deficient babies treated with artificial ventilation in the neonatal period.

Patients suffering from severe neonatal respiratory distress syndrome (RDS) frequently require assisted ventilation. In these patients, the obvious aims of the respirator treatment are to correct abnormal blood gas levels and to ensure survival with a minimum of long-term complications. This form of treatment, however, might turn into a cruise between Scylla and Charybdis; whereas high doses of oxygen and/or high insufflation pressure levels might be needed to increase the oxygenation of the patient, the same therapeutic measures clearly increase the risk of bronchopulmonary dysplasia $(4-6,29-31,33,35,37)$.
There is abundant clinical evidence that gas exchange in patients with RDS can be improved by application of positive endexpiratory pressure during spontaneous or artificial ventilation ( 2 , $3,8,11,34,36)$. This type of treatment apparently prevents alveolar collapse at end-expiration and thereby reduces the intrapulmonary shunting of blood through nonaerated units of the parenchyma. Studies on RDS patients have also indicated that a similar beneficial effect can be obtained during artificial ventilation by significant prolongation of the inspiration phase, i.e., by shifting the inspiration:expiration (I:E) ratio from conventional 1 : 2 or $1: 1$ to as much as $4: 1(32,33)$. However, this concept has apparently not been tested systematically in animal experimental models.

The purpose of the present study is to evaluate the influence of varying I:E ratios on lung mechanics in surfactant-deficient, preterm newborn rabbits. Such animals usually require artificial ventilation to survive the immediate neonatal period (20) and therefore serve as a useful model of patients with respiratory insufficiency due to prematurity.

\section{MATERIALS AND METHODS}

The experiments were carried out on a total of 32 newborn rabbits from four litters obtained on day 27 of gestation (term $=$ $31 \pm 1$ days). At this stage of development, the structure of the lungs is compatible with gas exchange, but adequate amounts of surfactant phospholipids have not yet accumulated in the air spaces $(10,16,24)$. Body weight of the experimental animals ranged between 17 and $44 \mathrm{~g}(\overline{\mathrm{X}} \pm \mathrm{SD}=34 \pm 7 \mathrm{~g})$.

The pregnant doe was killed by a rapid injection of $2 \mathrm{ml}$ sodium hexobarbital $(100 \mathrm{mg} / \mathrm{ml})$ and $5 \mathrm{ml}$ of potassium chloride $(40 \mathrm{mg} /$ $\mathrm{ml}$ ), and the fetuses were immediately delivered by hysterotomy. We tracheostomized the fetuses using a metal cannula as tracheal tube. The animals were operated on in sequence, and the average time for the tracheostomy procedure was approximately 2 min per fetus. Before and after the operation, the animals were kept at the environmental temperature of $38^{\circ} \mathrm{C}$ and stimulated to breathe by gentle manipulation. When all animals (maximal number/litter =9) had been tracheostomized, they were relaxed by intraperitoneal injection of $0.05 \mathrm{ml}$ of pancuronium bromide [Pavulon $(0.2$ $\mathrm{mg} / \mathrm{ml}$ ), Organon, Oss, Holland], transferred to a multichambered, pressure-constant body plethysmograph heated to $38^{\circ} \mathrm{C}$, and connected to a ventilator system designed for parallel ventilation of fetuses at varying frequencies and I:E ratios (Fig. 1). As a basis for this system, we used a modified Servo Ventilator 900 B (Siemens-Elema, Solna, Sweden), permitting variations in I:E ratio from $1: 4$ to $4: 1$. This equipment provides pressure-generated ventilation with decelerating flow using excess flow through the ventilator system. 
At the onset of artificial ventilation, the respirator was set at a frequency of $40 / \mathrm{min}, \mathrm{I}: \mathrm{E}$ ratio of $1: 1$, and working pressure of 35 $\mathrm{cm} \mathrm{H}_{2} \mathrm{O}$. The animals were ventilated under these conditions for $1 \mathrm{~min}$ (to overcome initial resistance due to capillarity in finer conducting airways) and then ventilated with the same frequency and I:E ratio at a pressure of $30 \mathrm{~cm} \mathrm{H}_{2} \mathrm{O}$ for approximately $5 \mathrm{~min}$. Initial values for tidal volume $\left(\mathrm{V}_{\mathrm{T}}\right)$ were then determined in each fetus with a specially designed Fleisch-tube (19) connected to the body plethysmograph, a differential pressure transducer (Siemens-

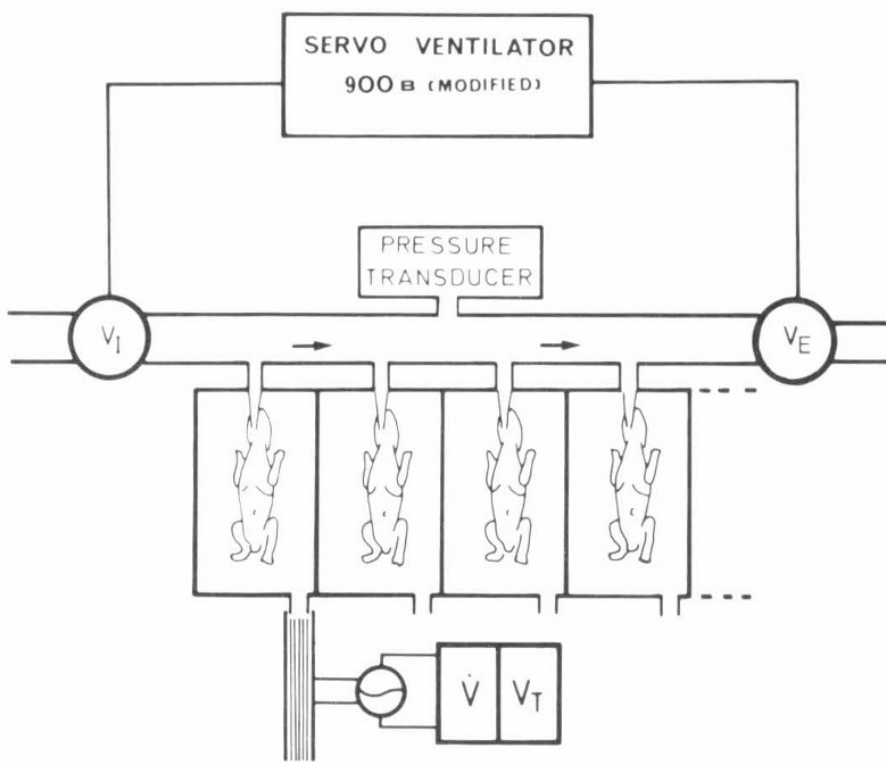

Fig. 1. Diagram of respirator system for parallel ventilation of multiple animals. Pressure is recorded close to the connections leading to the tracheal tubes, and flow $(\dot{V})$ and tidal volume $\left(\mathrm{V}_{\mathrm{T}}\right)$ by a pneumotachograph connected to each body plethysmograph via a Fleisch tube. $V_{I}$ and $V_{E}=$ inspiratory and expiratory valves.
Elema EMT 34), and amplifier (EMT 31), an integrator unit (EMT 41), and a recorder (Siemens-Elema Mingograf 81).

The setting of the ventilator was then changed, and the effect on $V_{T}$ of different $I: E$ ratios $(1: 4,1: 1$, and $4: 1)$ was tested at the frequencies 20,40 , and $60 / \mathrm{min}$ on an alternate basis at constant insufflation pressure $\left(30 \mathrm{~cm} \mathrm{H}_{2} \mathrm{O}\right)$, allowing 2 min of equilibration at each type of setting before recordings were made. In 16 animals (two litters), the protocol was extended to include two intermediate I:E ratios, 1:2 and 2:1. This prolongation of the experimental procedure resulted in a significantly increased incidence of pneumothorax and was therefore not applied in all litters. Finally, the animals were ventilated for two min with the same pattern as during the first recording $\left(30 \mathrm{~cm} \mathrm{H}_{2} \mathrm{O} ; 40 / \mathrm{min}\right.$; I:E ratio, $\left.1: 1\right)$, and $\mathrm{V}_{\mathrm{T}}$ was then registered as above. The course of the experiment in individual litters is illustrated diagrammatically in Figure 2.

At the end of the experiment, electrocardiogram tracings were obtained from each animal by needle electrodes and recorded on an oscilloscope (Biomonitor 501; Zwönitz, German Democratic Republic). Animals showing cardiac activity with regular QRScomplexes were counted as survivors.

Surviving animals were killed with an overdose of intraperitoneal sodium hexobarbital, their abdomens were opened, and the diaphragms were inspected for evidence of pneumothorax. Animals were included in the study only if they had survived the experimental procedure without developing pneumothorax or other complications related to air leakage.

We fixed the unopened thorax of the experimental animals in $10 \%$ formalin. The lungs were then embedded in paraffin, and 5 $\mu$-sections from the basal portions, stained with hematoxylin and eosin, were examined microscopically with particular reference to alveolar expansion pattern and to the degree of epithelial lesions in conducting airways.

\section{RESULTS}

Twenty animals survived the period of artificial ventilation without evidence of pneumothorax, pneumoperitoneum, or subcutaneous emphysema, and with a heart frequency of $>130 /$
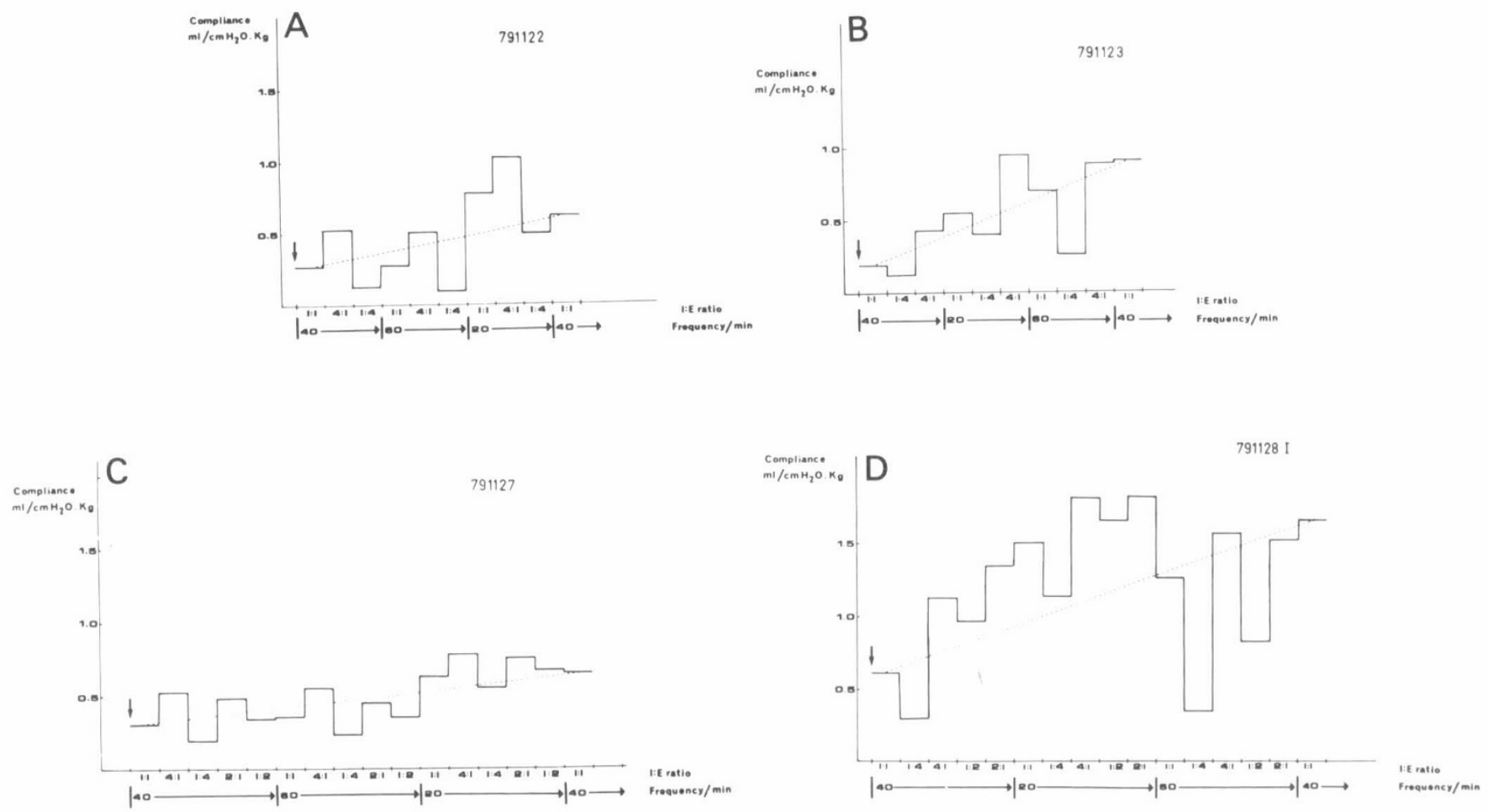

Fig. 2. Variations in lung-thorax compliance at different frequencies and inspiration:expiration (I:E) ratios. Mean values are given for litters studied in four separate experiments. Arrow, onset of artificial ventilation, and each I:E ratio period at the abscissa corresponds to approximately 2 min. In all experiments, there is a gradual "baseline drift" towards improved compliance, as indicated by broken lines. 
min at the end of the experimental procedure. Body weight of these animals ranged between 17 and $43 \mathrm{~g}(\overline{\mathrm{X}} \pm$ S.D. $=33 \pm 6 \mathrm{~g})$. Satisfactory recordings throughout the experimental period were obtained from 19 survivors.
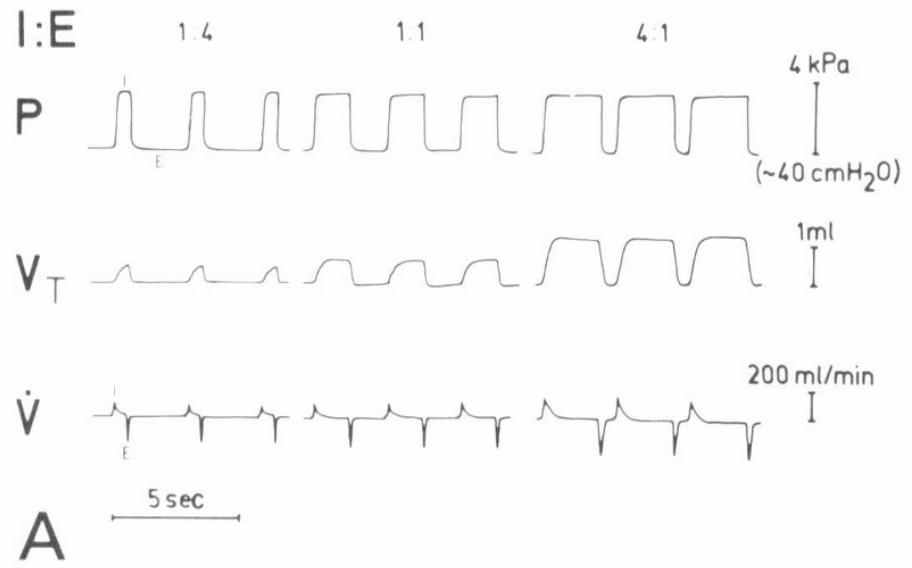

$$
791123-\text { F2 Frequency } 40 / \mathrm{min}
$$$$
\mathrm{I}: \mathrm{E}
$$$$
1: 4
$$

1.1
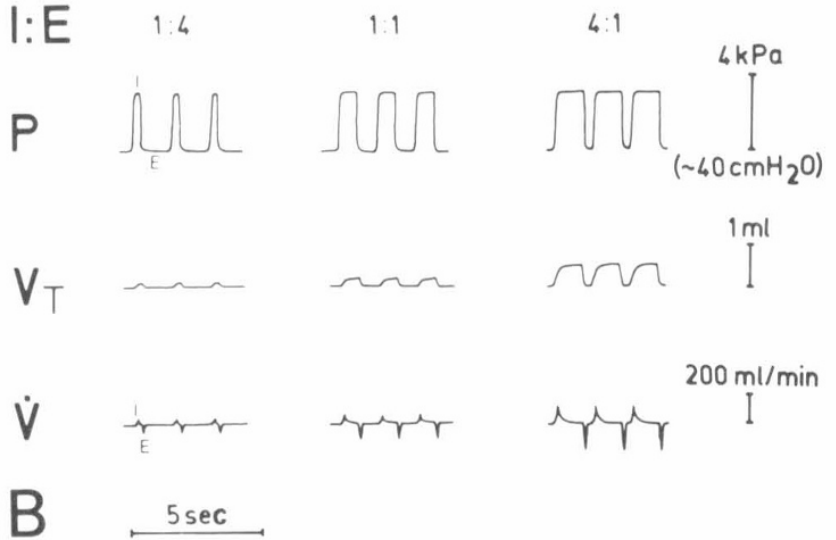

791123-F2 Frequency $60 / \mathrm{min}$

\section{I:E $\quad 14$

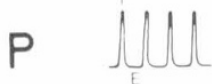

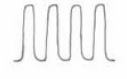

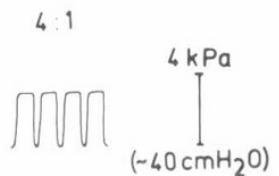

$V_{T}$
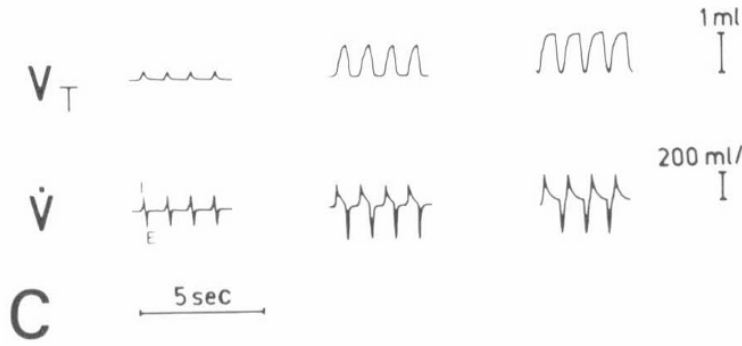

$5 \mathrm{sec}$
Fig. 3. Recordings of insufflation pressure $(P)$, tidal volume $\left(\mathrm{V}_{\mathrm{T}}\right)$, and flow $(\dot{V})$ at various frequencies and I:E ratios; all tracings shown in this diagram were obtained from the same animal. At all frequencies, increasing I:E ratio from $1: 4$ to $1: 1$ and further on to $4: 1$ leads to a significant enhancement of $V_{\mathrm{T}}$. Even at frequency $20 / \mathrm{min}$, at I:E ratio 1:4 inspiration flow does not return to zero before the onset of expiration. The flow tracing also shows that at frequency $60 / \mathrm{min}$ and I:E ratio $4: 1$, the duration of the expiration phase is short enough to prevent zero flow before onset of inspiration. $I=$ inspiration; $E=$ expiration.
EFFECT OF VARIATIONS IN I:E RATIO ON $\mathrm{T}_{\mathrm{T}}$

Irrespective of the respirator frequency, increasing the I:E ratio from the basic setting of 1:1 invariably resulted in enhanced $V_{T}$ (= increased lung-thorax compliance); decreasing the I:E ratio consistently had the opposite effect (Figs. 2 and 3).

During the course of the experiment, there was a baseline drift towards improved compliance in all surviving animals (Fig. 2). Relative volumes for each frequency were therefore calculated using figures obtained at an I:E ratio of $1: 1$ as reference values and compensating for the average baseline drift in each litter. Diagrams based on such "corrected" figures for $\mathrm{V}_{\mathrm{T}}$ show a nearly linear relation between variations in I:E ratio and $V_{T}$ (Fig. 4). However, the slope of the regression line was steeper for the higher frequencies ( 40 and $60 / \mathrm{min}$ ) than for frequency $20 / \mathrm{min}$.

Lung-thorax compliance was not simply related to mean airway pressure, but tended to decrease with increasing respiratory frequency at each I:E ratio. This variation was most prominent at an I:E ratio of 1:4 (Table 1).

Flow and volume tracings revealed that at high frequencies (40 and $60 / \mathrm{min}$ ) and low I:E ratios $(\leq 1: 1)$, the duration of the inspiration phase was, as a rule, not sufficient to provide the maximal degree of lung expansion attainable under static conditions with this insufflation pressure. This could be concluded from the fact that at end-inspiration the volume tracing had not reached a plateau, and flow had not returned to zero. The same tracings also showed that at low frequencies ( 20 and $40 / \mathrm{min}$ ), irrespective of I:E ratio, expiratory flow constantly returned to zero before next inspiration, whereas at high frequency $(60 / \mathrm{min})$ and high I: E ratio (4:1), the expiration phase was short enough to prevent zero flow before onset of inspiration (Fig. 3).

\section{HISTOLOGIC FINDINGS}

Lung aeration was irregular in all animals, and in large areas, the configuration of alveoli corresponded to the fetal, fluid-filled state. Focal intraalveolar hemorrhage was observed in most lungs, but there were no widespread hemorrhagic or inflammatory lesions. All animals showed necrosis and desquamation of bronchiolar epithelium, usually with prominent accumulation of desquamated cells in the terminal conducting airways (Fig. 5).

\section{COMMENT}

To provide adequate aeration of the liquid-filled lung at birth, the insufflation pressure must be high enough to overcome capillarity in the finer conducting airways $(1,9,12)$. Furthermore, this "opening pressure" must be applied for a period of time which is long enough to overcome viscosity of the fluid that has to be displaced from the bronchial tree as the air-liquid interface moves towards the alveoli (7). In the full-term newborn rabbit, for instance, the inspiration phase of the first breath is characterized by a transpulmonary pressure gradient in the order of $35 \mathrm{~cm} \mathrm{H}_{2} \mathrm{O}$ maintained for about $0.25 \mathrm{sec}$ (19). High insufflation pressure levels and prolonged inspiration phase have also been documented in recordings from the first breaths of newborn infants $(14,15,18$, 25 ). Another characteristic feature of normal neonatal adaptation is that functional residual capacity is established quickly after birth $(13,17)$. This adaptive phenomenon depends on surfactant phospholipids, which rapidly adsorb to the air-liquid interface and prevent alveolar collapse at end-expiration. In the surfactantdeficient lung, however, alveoli will tend to collapse at the end of each ventilatory cycle, and the resorption of fetal pulmonary fluid from the airspaces is delayed. This means that the air-liquid interfaces will return to the terminal conducting airways with each expiration; each single ventilatory cycle therefore requires the same efforts as normally demanded only for the first breaths. This is the pathophysiologic basis of RDS in surfactant-deficient premature newborn infants.

The same pathophysiologic mechanisms generate specific problems also during artificial ventilation. It is obvious from our present data that immature lungs are not effectively ventilated 

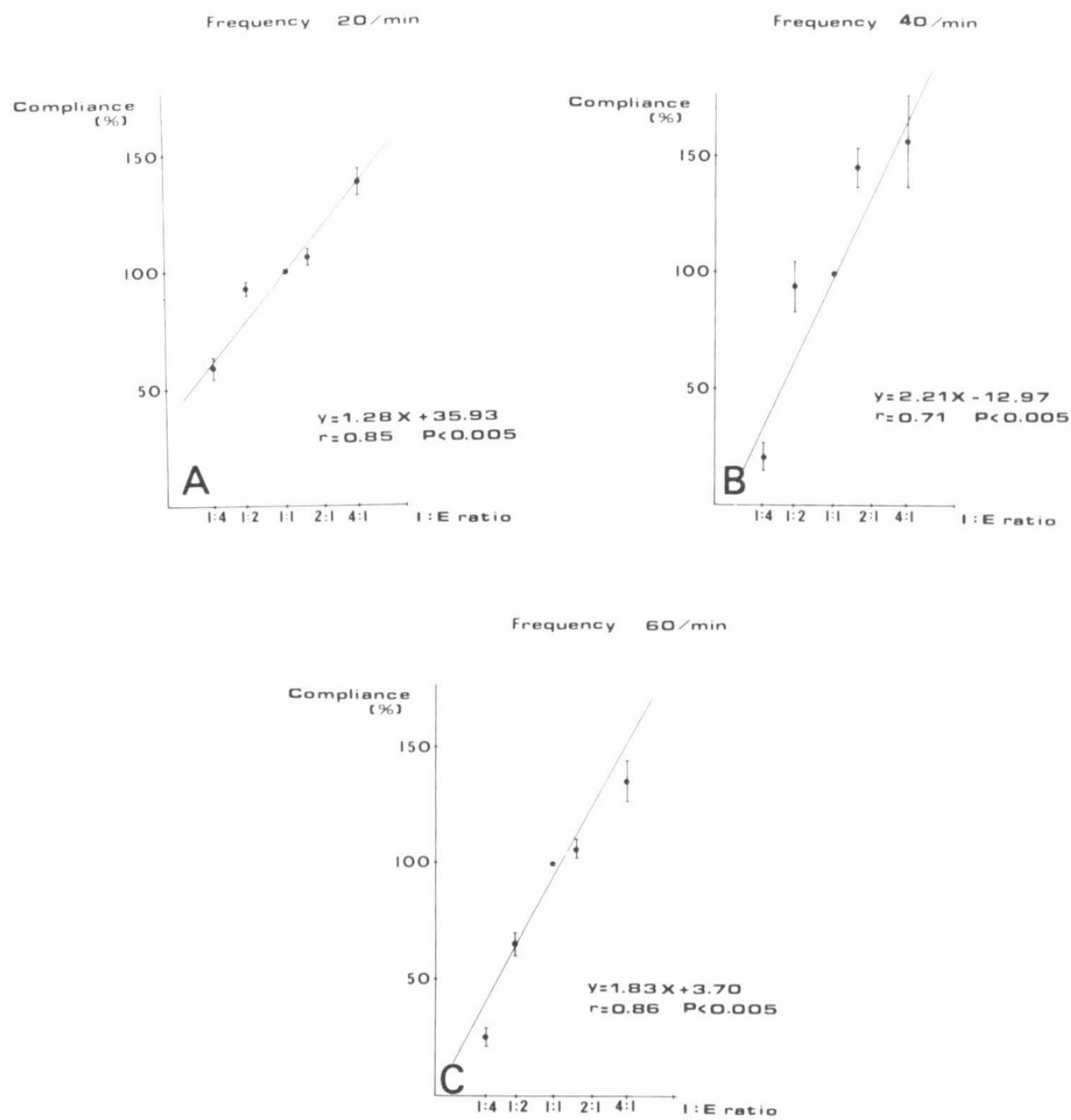

Fig. 4. Relation between I:E ratio and "relative" lung-thorax compliance $(\overline{\mathrm{X}} \pm \mathrm{SE})$ at various frequencies. At each frequency, the compliance figures are given as percentage of those obtained at I:E ratio 1:1. The figures are also corrected for the estimated baseline drift in each litter ( $c f$. Fig. 2).

Table 1. Lung-thorax compliance related to mean airway pressure and respiratory frequency ${ }^{1}$

\begin{tabular}{|c|c|c|c|c|}
\hline \multirow{2}{*}{$\begin{array}{c}\mathrm{I}: \mathrm{E} \\
\text { ratio }\end{array}$} & \multirow{2}{*}{$\begin{array}{l}\text { Mean } \\
\text { airway } \\
\text { pressure } \\
\left(\mathrm{cm} \mathrm{H}_{2} \mathrm{O}\right)\end{array}$} & \multicolumn{2}{|c|}{$\begin{array}{c}\text { Compliance } \\
\left(\mathrm{ml} / \mathrm{cm} \mathrm{H}_{2} \mathrm{O} \cdot \mathrm{kg}, \overline{\mathrm{X}} \pm \mathrm{S} . \mathrm{D} .\right) / \\
\text { frequency }(\text { per min) }\end{array}$} & \multirow[b]{2}{*}{$P<$} \\
\hline & & 20 & 60 & \\
\hline $1: 4$ & 6 & $0.50 \pm 0.26$ & $0.21 \pm 0.10$ & 0.002 \\
\hline $1: 1$ & 15 & $0.69 \pm 0.41$ & $0.52 \pm 0.32$ & $0.2(\mathrm{NS})$ \\
\hline $4: 1$ & 24 & $0.99 \pm 0.42$ & $0.73 \pm 0.36$ & 0.1 (NS) \\
\hline
\end{tabular}

${ }^{1}$ The values are calculated from original observations, uncorrected for baseline drift. Data are given for the two frequencies that were applied on an alternate basis during the middle of the experimental period ( $c f$. Fig. 2).

with a conventional $\mathrm{I}$ : $\mathrm{E}$ ratio of $1: 1$ or less. At each frequency studied, there was a nearly linear correlation between I:E ratio and lung-thorax compliance, indicating that the prolonged inspiration phase was needed to overcome viscosity of nonresorbed fetal pulmonary fluid in the air spaces. Our data furthermore indicate that the compliance of the surfactant-deficient lung is modified not only by the duration of the inspiration phase but also by the duration of the expiration phase. This is suggested by the observation that expiratory flow never returned to zero level in animals ventilated with a frequency of $60 / \mathrm{min}$ and I:E ratio of $4: 1$. Under these conditions, the lungs were therefore not allowed to collapse between each ventilatory cycle. With all other ventilator settings, flow returned to zero before the end of the expiration phase.

It is a well-known fact that collapse of surfactant-deficient alveoli can be prevented by application of positive end-expiratory pressure (PEEP). In the artificially ventilated immature rabbit neonate, treatment with PEEP also increases lung compliance and reduces the development of bronchiolar epithelial lesions (26) PEEP was not used in the present study, however, because we were mainly interested in the isolated effects of variations in I:E ratio on lung mechanics. Moreover, because various I:E ratios were applied in each animal, our present data do not permit analysis of lung morphology in relation to the setting of the ventilator. Previous studies have shown that epithelial lesions, similar to those documented above, develop in immature newborn rabbits within $5 \mathrm{~min}$ of conventional artificial ventilation unless the animals receive supplementary surfactant at birth $(27,28)$

The lungs of animals or patients with surfactant deficiency are most effectively ventilated with a pressure-constant, time-cycled respirator with decelerating flow $(21-23,32)$. In the present study, all animals were ventilated in parallel with such an equipment using standardized insufflation pressure, irrespective of individual variations in lung-thorax compliance. Animals with highly compliant lungs were therefore greatly overventilated, especially when high I:E ratios were applied, and several of these animals developed pneumothorax or related complications due to rupture of the lungs. This illustrates the importance of individual setting of the respirator system. For each experimental animal (or each patient 


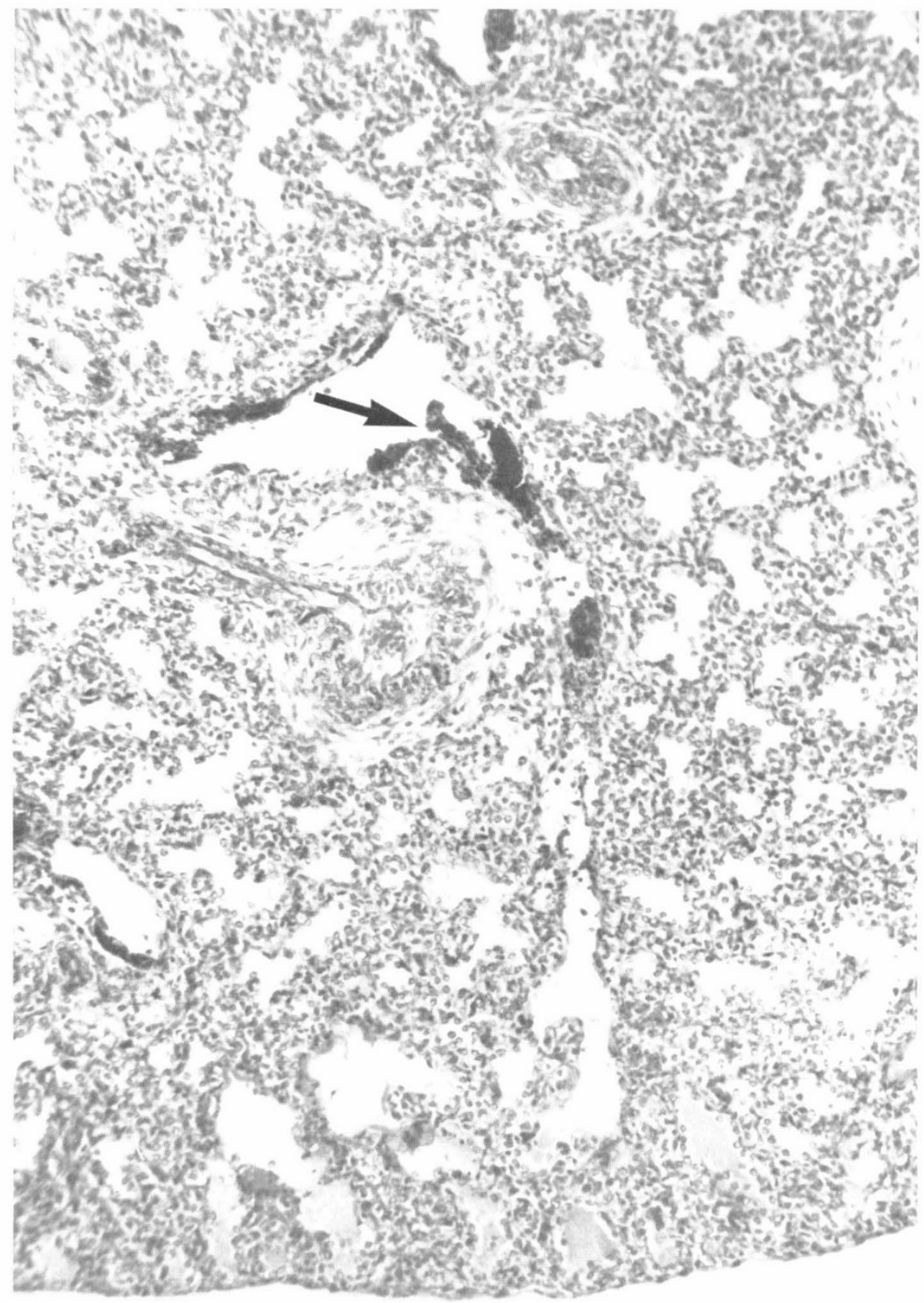

Fig. 5. Histologic section of lung lobule from experimental animal, showing poor aeration of alveoli and extensive necrosis and desquamation of bronchiolar epithelium ( arrow). Abundant unresorbed fetal pulmonary fluid in subpleural air spaces (lower). Hematoxylin and eosin, $\times 150$. with surfactant deficiency), there is an optimal setting of the ventilator which can be arrived at by testing the effect of variations in frequency, I:E ratio, peak pressure, and PEEP on gas exchange and cardiac function.

\section{REFERENCES AND NOTES}

1. Agostoni, E., Taglietti, A., Agostoni, A., and Setnikar, I.: Mechanical aspects of the first breath. J. Appl. Physiol., 13: 344 (1958).

2. Ahlström, H., Jonson, B., and Svenningsen, N. W : Continuous positive airway pressure with a face chamber in the early treatment of idiopathic respiratory distress syndrome. Acta Paediatr. Scand., 62: 433 (1973).

3. Ahlström, H., Jonson, B., and Svenningsen, N.W.: Continuous positive airways pressure treatment by a face chamber in idiopathic respiratory distress syndrome. Arch. Dis. Child., 51: 13 (1976).

4. Anderson, W. R., and Strickland, M. B.: Pulmonary complications of oxygen therapy in the neonate: post-mortem study of bronchopulmonary dysplasia with emphasis on fibroproliferative bronchitis and bronchiolitis. Arch. Pathol.. 91: 506 (1971)
5. Banerjee, C. K., Girling, D. J., and Wigglesworth, J. S.: Pulmonary fibroplasia in newborn babies treated with oxygen and artificial ventilation. Arch. Dis. Child., 47: 509 (1972).

6. Bonikos, D. S., Bensch, K. G., Northway, W. H., Jr., and Edwards, D. K. Bronchopulmonary dysplasia: The pulmonary pathologic sequel of necrotizing bronchiolotis and pulmonary fibrosis. Hum. Pathol., 7: 643 (1976).

7. Chernick, V.: Mechanics of the first inspiration. Semin. Perinatol., 1: 347 (1977).

8. Cumarasamy, N., Nüssli, R., Vischer, D., Dangel, P. H., and Duc, G. V.: Artificial ventilation in hyaline membrane disease: The use of positive end-expiratory pressure and continuous positive airway pressure. Pediatrics, 51: 629 (1973).

9. Enhörning, G., and Robertson, B.: Lung expansion in the premature rabbit fetus after tracheal deposition of surfactant. Pediatrics, 50: 58 (1972).

10. Gluck, L., Motoyama, E. K., Smits, H. L., and Kulovich. M. V.: The biochemica development of surface activity in mammalian lung. I. The surface active phospholipids; the separation and distribution of surface active lecithin in the lung of the developing rabbit fetus. Pediatr. Res., 1: 237 (1967).

11. Gregory, G. A., Kitterman, J. A., Phibbs, R. H., Tooley, W. H., and Hamilton. W. K.: Treatment of the idiopathic respiratory distress syndrome with continuous positive airway pressure. N. Engl. J. Med., 284: 1333 (1971).

12. Gruenwald, P.: Surface tension as a factor in the resistance of neonatal lungs to 
aereation. Am. J. Obstet. Gynecol., 53: 996 (1947).

13. Guebelle, F., Karlberg, P., Koch, G., Lind, J., Wallgren, G., and Wegelius, C.: L'aeration du poumon chez nouveau-né. Biol. Neonate, 1:169 (1959).

14. Karlberg, P.: The adaptive changes in the immediate neonatal period, with particular reference to respiration. J. Pediatr., 56: 585 (1960).

15. Karlberg, P., Cherry, R. B., Escardo F. E., and Koch, G.: Respiratory studies in newborn infants. II. Pulmonary ventilation and mechanics of breathing in the first few minutes of life, including the onset of respiration. Acta Paediatr., 51: 121 (1962).

16. Kikkawa, Y., Motoyama, E. K., and Gluck, L.: Study of the lungs of fetal and newborn rabbits. Morphologic, biochemical and surface physical development. Am. J. Pathol., 52: 177 (1968).

17. Klaus, M., Tooley, W. H., Weaver, K. H., and Clements, J. A.: Lung volume in the newborn infant. Pediatrics, 30: 111 (1962).

18. Lachmann, B.: Neonatal pulmonary mechanics during spontaneous ventilation. Rev. Perinat. Med. 4: (in press).

19. Lachmann, B., Grossmann, G., Nilsson, R., and Robertson, B.: Lung mechanics during spontaneous ventilation in premature and full-term rabbit neonates. Respir. Physiol., 38: 283 (1979).

20. Lachmann, B., Grossmann, G., Nilsson, R., and Robertson, B.: Effect of supplementary surfactant on in vivo lung mechanics in the premature rabbit neonate. Eur. J. Pediatr. (in press).

21. Lachmann, B., Haendly, B., Schultz, H., and Jonson, B.: Improved arterial oxygenation, $\mathrm{CO}_{2}$ elimination, compliance and decreased barotauma following changes of volume-generated PEEP ventilation with inspiratory/expiratory (I/ E)-ratio of 1:2 to pressure-generated ventilation with $1 / E$-ratio of $4: 1$ in patients with severe adult respiratory distress syndrome. Intensive Care Med., 6: 64 (1980).

22. Lachmann, B., Robertson, B., Danzmann, E., Hohmann, H., Kayser, P., Oddoy, A., Bomm. M. Voigt, H., and Jonson, B.: Reduced barotrauma and reduced detrimental hemodynamic effects in dogs with acute respiratory failure (ARF) using an inspiratory/expiratory ratio (I/E) of 4:1. Intensive Care Med., 6: 68 (1980).

23. Manginello, F. P., Grassi, A. E., Scherchner, S., Krauss, A. N., and Auld, P. A.: Evaluation of methods of assisted ventilation in hyaline membrane disease. Arch. Dis. Child, 53: 878 (1978).

24. Meyrick, B., and Reid, L.: The alveolar wall. Br. J. Dis. Chest., 64: 121 (1970).

25. Milner, A. D., and Saunders, R. A.: Pressure and volume changes during the first breath of human neonates. Arch. Dis. Child., 52: 918 (1977).

26. Nilsson, R., Grossmann, G., and Robertson, B.: Artificial ventilation of premature newborn rabbits; effects of positive end-expiratory pressure on lung mechanics and lung morphology. Acta Paediat. Scand.. 69: 597 (1980).

27. Nilsson, R., Grossmann, g., and Robertson, B.: Bronchiolar epithelial lesions induced in the premature rabbit neonate by short periods of artificial ventilation. Acta Pathol. Microbiol. Scand. A Pathol., 88: 359 (1980).

28. Nilsson, R., Grossmann, G., and Robertson, B.: Pathogenesis of neonatal lung lesions induced by artificial ventilation; evidence against the role of barotrauma. Respiration, 40:218 (1980).

29. Northway, W. H., Jr., Rosan, R. C., and Porter, D. Y.: Pulmonary disease following respirator therapy of hyaline membrane disease. Bronchopulmonary dysplasia. N. Engl. J. Med., 276: 357 (1967).

30. Philip, A. G. S.: Oxygen plus pressure plus time: the etiology of bronchopulmonary dysplasia. Pediatrics, 55: 44 (1975).

31. Pusey, V. A., MacPherson, R. I., and Chernick, V.: Pulmonary fibroplasia following prolonged artificial ventilation of newborn infants. Can. Med. Assoc. J., 100: 451 (1969).

32. Reynolds, E. O. R.: Effect of alterations in mechanical ventilator setting on pulmonary gas exchange in hyaline membrane disease. Arch. Dis. Child., 46: 152 (1971).

33. Reynolds, E. O. R., and Taghizadeh, A.: Improved prognosis of infants mechanically ventilated for hyaline membrane disease. Arch. Dis. Child.. 49: 505 (1974).

34. Richardson, C. P., and Jung, Al.: Effects of continuous positive airway pressure on pulmonary function and blood gases of infants with respiratory distress syndrome. Pediatr. Res., 12: 771 (1978).

35. Rosan, R. C.: Hyaline membrane disease and a related spectrum of neonatal pneumopathies. In: H. S. Rosenberg, R. P. Bolande: Perspectives in Pediatric Pathology, Vol. 2, pp. 15-60 (Year Book Medical Publishers, Chicago, 1975).

36. Svenningsen, N. W., Jonson, B.. Lindroth, M., and Ahlstrom, H.: Consecutive study of early CPAP-application in hyaline membrane disease. Eur. J. Pediatr. 131: 9 (1979)

37. Taghizadeh, A., and Reynolds, E. O. R.: Pathogenesis of bronchopulmonary dysplasia following hyaline membrane disease. Am. J. Pathol., 82: 241 (1976).

38. Requests for reprints should be addressed to: Dr. Bengt Robertson, Pediatric Pathology Research Laboratory, St. Göran's Hospital, S-112 81 Stockholm. Sweden.

39. This research was supported in part by The Swedish Medical Research Council (project No. 3351).

40. Received for publication July 22, 1980

41. Accepted for publication October 23, 1980. 